\begin{tabular}{|cc|}
\hline AUTOMOBILE & INDOOR \\
VEHICLES & PASSENGERS \\
EXPIRATION & METABOLISM \\
EXHAUST & HYDROCARBONS \\
SAMPLING & GC - MS \\
\hline
\end{tabular}

Open access revised manuscript version of Sci. Total Environ. 207 (1997) 63-67 doi:10.1016/S0048-9697(97)00248-9

\title{
Isoprene from expired air inside a private car
}

Susan Björkqvist, Anders Spetz, Olle Ramnäs and Göran Petersson

Preceding analytical studies of hydrocarbons including isoprene deal with tobacco smoke and air pollution from traffic exposure in commuter trains and buses 


\title{
Isoprene from expired air inside a private car
}

\author{
Susan Björkqvist, Anders Spetz, Olle Ramnäs and Göran Petersson. \\ Department of Chemical Environmental Science, Chalmers University of Technology, 41296 Göteborg, Sweden
}

\begin{abstract}
The concentration of isoprene inside a small-size parked private car with one person was found to be of the order of $20 \mu \mathrm{g} / \mathrm{m}^{3}$. Isoprene was then the major non-methane volatile hydrocarbon except in strongly traffic-polluted parking places. On driving, with intermediate fan ventilation, the isoprene levels were one order of magnitude lower. In the empty car, the concentrations were still much lower, proving that isoprene originates predominantly from expired air.
\end{abstract}

Air samples were taken on triple-layer adsorbent cartridges and were analysed for volatile hydrocarbons by gas chromatography after thermal desorption. The analytical aluminium oxide column permitted simultaneous determination of a range of reported trafficemitted hydrocarbons including the carcinogenic 1,3-butadiene and benzene.

Keywords: Isoprene; Human breath; Automobiles; Adsorbent sampling; Gas chromatography 


\section{Introduction}

Human exposure to air pollutants inside vehicles is often important because of high concentrations relative to most urban environments (Barrefors and Petersson, 1993 and 1996). Determination of specific compounds and specific sources is therefore of great interest.

Isoprene was early identified as a major organic compound in human expired air (Jansson and Larsson, 1969). This may result in significant concentrations in indoor environments such as classrooms (Cailleux et al., 1993), whereas outdoor concentrations are negligible due to rapid dilution. Isoprene is also a major volatile hydrocarbon in tobacco smoke causing high concentrations in smoky indoor environments (Barrefors and Petersson, 1993).

Recently, isoprene has caused concern because of its structural and metabolic similarity with the carcinogenic 1,3-butadiene (Gervasi and Longo, 1990). Reactions of isoprene with ozone and with the hydroxyl radical may also be important in enclosed human environments (Weschler and Shields, 1996).

In a previous study, significant concentrations of isoprene were observed inside local and commuter buses with many passengers (Barrefors and Petersson, 1996). The purpose of this study was to investigate the occurrence of isoprene in relation to other hydrocarbons inside a private car.

\section{Methods}

\subsection{Sampling}

A small-size private car (Nissan Micra, model 1988, three-way catalyst) was used for taking in-vehicle samples. All samples were taken during a windy period in April 1997. The 
air temperature inside the car during sampling was in the range $15-20^{\circ} \mathrm{C}$. The person inside the car was one of the male non-smoking authors, sitting in the driver's seat.

Samples representing parking with many surrounding cars were taken on a large parking lot with more than one hundred parked cars. The car was parked at least one hour before sampling with the windows left partially open. The exhaling person sat for 10 min inside the car with closed windows before starting the sampling which proceeded for a further $10 \mathrm{~min}$ period. Samples representing isolated parking without adjacent cars were taken similarly in a suburban well ventilated area. In this case, the car was parked during the night before sampling.

Sampling during suburban diiving was made in an area with little traffic, few stops and no queues. Corresponding urban sampling was performed during driving in streets with moderate traffic, including a few stops near behind other cars at traffic lights. During sampling (10 $\mathrm{min})$ and the preceeding equilibration time $(10 \mathrm{~min})$, the windows were closed and the external ventilation set to intermediate speed. Initially, the car was run for at least $10 \mathrm{~min}$ to ascertain proper catalyst function. The windows were kept partially open during this driving period.

Triple-layer glass cartridges of the same design as in previous studies (Barrefors and Petersson, 1993) were used. The adsorbents were Tenax TA, Carbotrap and Carbosieve S-III in order of increasing adsorption strength. The cartridges were placed near the steering wheel and were connected to small air pumps. The sampled air volumes were of the order $400 \mathrm{ml}$ and were accurately determined from the pump flows.

Breath samples were taken by expiring air through a drying cartridge $(10 \mathrm{~cm}$ glass tube with $0.5-1 \mathrm{~g}$ of $\left.\mathrm{MgClO}_{4}\right)$ connected to the sampling cartridge. The volume $(15-20 \mathrm{ml})$ of 
expired air was determined by connecting a glass syringe $(20$ or $30 \mathrm{ml})$ with freely moving piston to the outlet of the adsorption cartridge. The samples were taken after completed normal expiration during continued forced expiration. Pulling a few $\mathrm{ml}$ of ambient air through the adsorbent cartridge after sampling ascertained complete passing of the expired air.

\subsection{Gas chromatography}

Thermal desorption and gas chromatography were performed basically as in previous studies of volatile hydrocarbons in urban air (Barrefors and Petersson, 1993). Desorption (He, $10 \mathrm{ml} / \mathrm{min}, 200^{\circ} \mathrm{C}, 10 \mathrm{~min}$ ) was made into a cold trap (empty fused silica column coil, $5 \mathrm{~m} \mathrm{x}$ $0.32 \mathrm{~mm}$ i.d., in liquid $\left.\mathrm{N}_{2}\right)$. A drying cartridge with $\mathrm{MgClO}_{4}(0.5-1 \mathrm{~g})$ was placed between the desorption oven and the cold trap. Switching the trap into the carrier gas line followed by rapid heating $\left(120^{\circ} \mathrm{C}\right.$ in an oil bath) moved the trapped compounds into the analytical column.

The separations were performed by gas-solid chromatography on an aluminium oxide column ( $50 \mathrm{~m} \mathrm{x} 0.32 \mathrm{~mm}$ i.d., fused silica porous-layer open tubular, $\mathrm{Al}_{2} \mathrm{O}_{3}$ with $5 \% \mathrm{KCl}$, Chrompack). The carrier gas was helium $(20-30 \mathrm{~cm} / \mathrm{s})$. The temperature of the column oven was rapidly increased from ambient to $100^{\circ} \mathrm{C}$ and then linearly by $4^{\circ} \mathrm{C} / \mathrm{min}$ to $200^{\circ} \mathrm{C}$ as the maximum temperature recommended for the column. The sensitivity of the flame ionisation detector was improved by the use of make-up gas $\left(\mathrm{N}_{2}, 20 \mathrm{ml} / \mathrm{min}\right)$. The response was set equal for all hydrocarbons, permitting data for reliable alkane references to be used.

\section{Results and discussion}

The results in Table 1 and the chromatograms in Figure 1 represent the most essential outcome of the study. 
Table 1

Concentrations $\left(\mu \mathrm{g} / \mathrm{m}^{3}\right)$ of isoprene and specific vehicle-emitted hydrocarbons for a comparative set of air samples

\begin{tabular}{lcccccc}
\hline & $\begin{array}{c}1 \\
\text { in car } \\
\text { one person } \\
\text { parked } \\
\text { isolated }\end{array}$ & $\begin{array}{c}\text { in car } \\
\text { one person } \\
\text { parked } \\
\text { car park }\end{array}$ & $\begin{array}{c}\text { in car } \\
\text { one person } \\
\text { driving } \\
\text { suburban }\end{array}$ & $\begin{array}{c}\text { in car } \\
\text { one person } \\
\text { driving } \\
\text { urban }\end{array}$ & $\begin{array}{c}\text { in car } \\
\text { empty } \\
\text { parked } \\
\text { car park }\end{array}$ & $\begin{array}{c}\text { in street } \\
\text { crossing } \\
\text { walking } \\
\text { urban }\end{array}$ \\
\hline Alkadienes & & & & & & \\
Isoprene & 18.0 & 18.5 & 2.0 & 2.4 & 0.1 & 0.3 \\
1,3-Butadiene & 0.1 & 0.2 & 0.1 & 1.0 & 0.1 & 0.6 \\
& & & & & & \\
Arenes & 1.8 & 3.9 & 2.5 & 14.9 & 4.2 & 8.1 \\
Benzene & 4.4 & 13.2 & 4.8 & 48.6 & 10.8 & 16.6 \\
Methylbenzene & & & & & & \\
Alkanes & & & & & & \\
Methylpentane & 1.8 & 11.4 & 2.5 & 29.2 & 9.7 & 7.6 \\
$\begin{array}{l}\text { Pentane } \\
\text { Hexane }\end{array}$ & 0.7 & 3.5 & 0.8 & 7.5 & 3.0 & 2.3 \\
& 0.2 & 1.2 & 0.3 & 3.1 & 0.8 & 0.9 \\
\hline
\end{tabular}



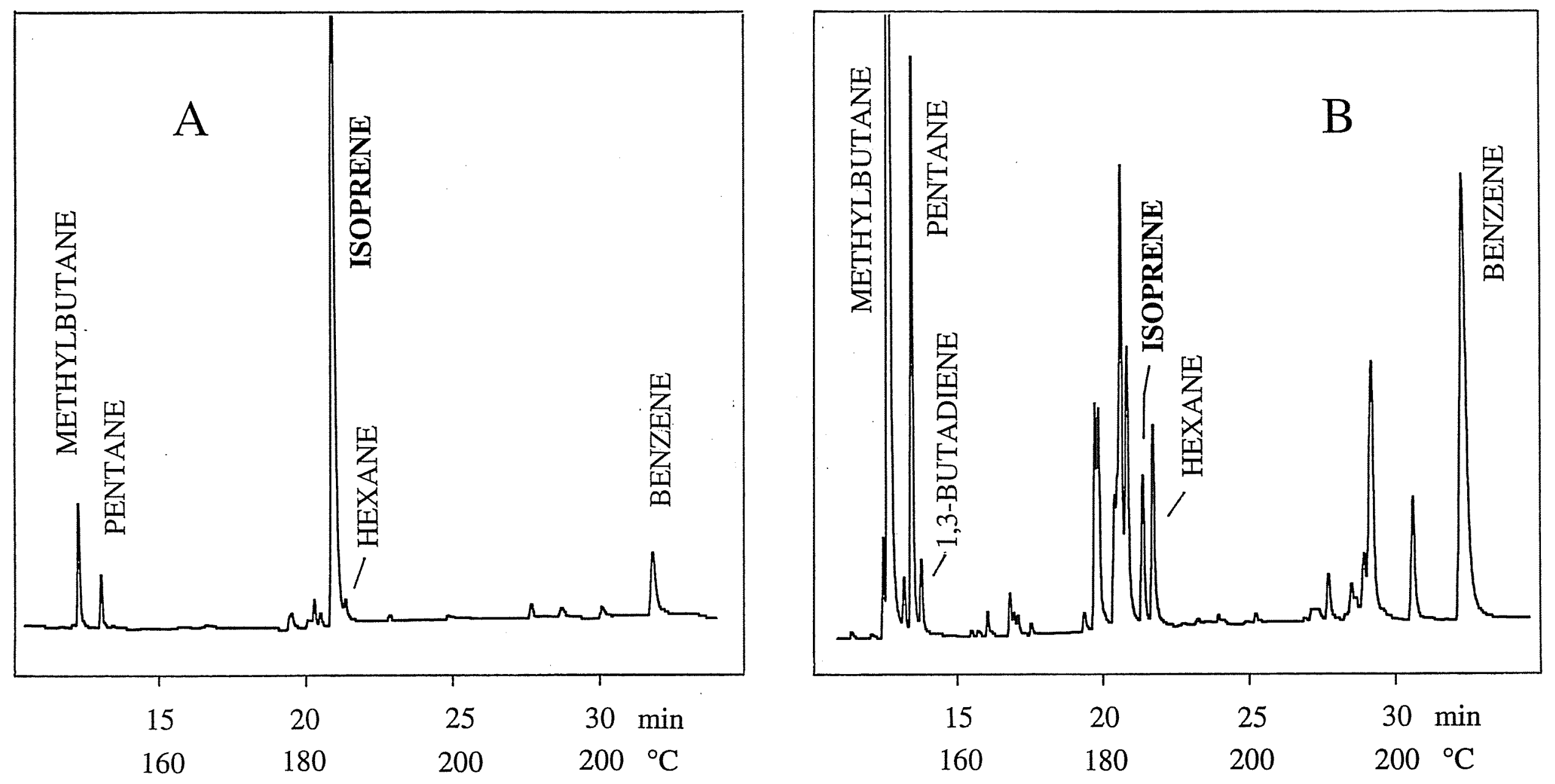

Figure 1. Gas chromatographic separation of isoprene and vehicle-emitted hydrocarbons on an aluminium oxide column.

A. One person in parked car without adjacent vehicles (sample 1 in Table 1).

B. One person in car in urban traffic (sample 4 in Table 1). 


\subsection{Isoprene}

Several experiments with the same male non-smoker in the same closed small car demonstrated isoprene concentrations in the range $15-25 \mu \mathrm{g} / \mathrm{m}^{3}$ after $15 \mathrm{~min}(10-20 \mathrm{~min})$. On driving, with intermediate fan ventilation, analogous samples demonstrated one order of magnitude lower concentrations. The very low concentrations (below $0.5 \mu \mathrm{g} / \mathrm{m}^{3}$ ) observed in the empty car and in external street air confirmed that expired air was the predominant source of isoprene in the car both when parked and on driving.

The isoprene concentration of expired alveolar air from the same person was of the order of $500 \mu \mathrm{g} / \mathrm{m}^{3}$ as assessed for several samples. Concentrations in alveolar air of humans, as reported in the literature, are in the range $500-1500 \mu \mathrm{g} / \mathrm{m}^{3}$ during daytime (DeMaster and Nagasawa, 1978; Cailleux and Allain, 1989). Diurnal variations are large with 2-3 times higher concentrations during sleep. It is concluded that higher isoprene concentrations than those in Table 1 are to be expected in the car from persons with higher than average concentrations in expired air, and particularly from the added contributions of two, three or four persons in the same car. During driving, decreased ventilation rate, low speed and frequent stops are expected to increase the isoprene concentrations.

\subsection{Vehicle-emitted hydrocarbons}

The hydrocarbons reported in Table 1 were selected as interesting for comparisons with isoprene. The carcinogenic 1,3-butadiene and benzene stand out as particular health hazards. Methylbenzene (toluene) is the most prominent hydrocarbon in petrol. Methylpentane, followed by pentane, is normally the most prominent hydrocarbon in petrol 
vapours. The origin of specific hydrocarbons in urban air and in buses was recently discussed in more detail (Barrefors and Petersson, 1996).

Except for isoprene, the concentration ratios for the hydrocarbons in the six samples reported in Table 1 are similar to those observed for traffic-polluted urban air (Barrefors and Petersson, 1993). All samples were taken during a windy period, and the concentrations are therefore lower than average. For samples 2 and 5, many closely surrounding parked cars explain the elevated proportions of pentanes from petrol vapour. Sample 1 corresponds to isolated parking and sample 3 to driving in a suburban area with low levels of vehicle-emitted air pollutants. The low concentrations in the car demonstrate that the contributions from the car itself may be kept low, at least after long parking time and on driving with warm engine and warm catalyst system. Sample 4 represents urban driving with fluctuating surrounding air pollution levels during sampling. Sample 6 was taken during walking around a street crossing with traffic lights and moderate traffic. Anticipated significant concentrations of the combustion-formed exhaust-emitted 1,3-butadiene (Barrefors and Petersson, 1993) were observed for these two samples. Interestingly, the street crossing sample demonstrates small traffic emissions of isoprene giving rise to concentrations about half of those of 1,3-butadiene.

The representativity of the samples in Table 1 and the conclusions made were supported by several repeated samples corresponding to the different circumstances discussed.

\subsection{Analytical aspects}

The chromatograms in Figure 1 illustrate the separation of isoprene and other reported hydrocarbons. Isoprene elutes between 3-methylpentane and hexane after several other cyclic 
and branched $\mathrm{C} 6$ alkanes. The position of isoprene relative to 3-methylpentane and hexane depends on the average column temperature during elution, and the choice of temperature program is therefore critical for the separation. The worrying 1,3-butadiene elutes after methylpentane and pentane but before a number of minor pentenes. Benzene appears after a number of $\mathrm{C} 7$ alkanes and cycloalkanes. Methylbenzene elutes $20 \mathrm{~min}$ after benzene during the final isothermal $\left(200^{\circ} \mathrm{C}\right)$ part of the temperature program. The separation of a wider range of volatile hydrocarbons has been demonstrated in previous studies (Barrefors and Petersson, 1993 and 1996).

For improved analytical quality, several precautions were observed. Drying cartridges containing $\mathrm{MgClO}_{4}$ were used to remove water both during sampling of expired air and after the desorption oven. This prevented ice plugs during trapping and improved chromatographic quality. No losses of the hydrocarbons studied were observed on the drying cartridges. Minor artefact formation of benzene from the adsorbent cartridges in the desorption oven was reduced by keeping the desorption temperature low. Losses of alkadienes like 1,3-butadiene and isoprene on the triple-layer adsorption cartridges have been observed after taking samples with unusually high concentrations of nitrogen oxides, but such samples were not taken in this investigation. Quantitative recovery even at the lowest concentrations was indicated by proper concentration ratios between the hydrocarbons studied.

\subsection{Human health impacts}

The endogenic character of isoprene makes it natural to balance potential beneficial functions against potential harmful effects. Biochemically activated derivatives of isoprene are involved in the biosynthesis of a wide range of human isoprenoid compounds. The high 
concentration of free isoprene in expired air has been linked to regulatory effects on sleep (Cailleux and Allain, 1989). The monoepoxides formed by metabolism of isoprene (methyl1,3-butadiene) appear not to be mutagenic in contrast to that formed from 1,3-butadiene. The potentially formed diepoxide is mutagenic for both alkadienes, however (Gervasi and Longo, 1990). The highest recorded ambient concentrations of isoprene in this study are of the order of only $10 \%$ of those in alveolar air. Direct physiological effects of ambient isoprene are therefore expected to be small.

A potentially more important aspect on ambient isoprene is chemical interactions with air pollutants. Reactions with ozone produces hazardous species such as formaldehyd and radicals. Nitrogen oxides are often present in high concentrations in vehicles and may produce harmful reaction products with reactive hydrocarbons. On the other hand, isoprene may act as a scavenger of reactive species such as the hydroxyl radical (Weschler and Shields, 1996). From this point of view, isoprene in expired air may be regarded as a chemical barrier against harmful reactive compounds in ambient air.

\section{References}

Barrefors, G. and Petersson, G. (1993) Assessment of ambient volatile hydrocarbons from tobacco smoke and from vehicle emissions. J. Chromatogr. 643, 71-76.

Barrefors, G. and Petersson, G. (1996) Exposure to volatile hydrocarbons in commuter trains and diesel buses. Environ. Technol. 17, 643-647.

Cailleux, A. and Allain, P. (1989) Isoprene and sleep. Life Sciences 44, 1877-1880.

Cailleux, A., Turcant, A., Premel-Cabic, A. and Allain, P. (1993) Volatile organic compounds in indoor air and in expired air as markers of activities. Chromatographia 37, 57-59. 
DeMaster, E. G. and Nagasawa, H. T. (1978) Isoprene, an endogenous constituent of human alveolar air with a diurnal pattern of excretion. Life Sciences 22, 91-98.

Gervasi, P. G. and Longo, V. (1990) Metabolism and mutagenicity of isoprene. Environ. Health Perspect. 86, 85-87.

Jansson, B. O. and Larsson, B. T. (1969) Analysis of organic compounds in human breath by gas chromatography - mass spectrometry. J. Lab. \& Clin. Med. 74, 961-965.

Weschler, C. J. and Shields, H. C. (1996) Production of the hydroxyl radical in indoor air. Environ. Sci. Technol. 30, 3250-3258. 